\title{
Prácticas de enseñanza mediadas por la tecnología Cómo enseñan los docentes en los foros de discusión de cursos que se desarrollan en modalidad a distancia*
}

\author{
Mag. Wellington Mazzotti**
}

\begin{abstract}
This work shows the results of a research on educational practices carried out by different teachers during newsgroups' discussions about e-learning in three educational centres -two in Argentina and one in Uruguay- with varied proposals and formats. The studied discussion groups were closed, only taking part in them the students there enrolled. The underlying concept of the research is that discussion groups are the main tools of any proposal for e-learning. Its power lies in the fact that through such groups it is possible to organise the socialisation of a virtual group, outlining a community of individuals related to each other and with the common aim of building knowledge. This way of communication transmits the observations and the analysis of the teachers' participation at the studied discussion groups within the research's framework. Among other considerations, it is shown how the role of a teacher transcends the institutional proposal. Within similar course formats, teachers assume very different roles and lead the discussion groups in such different ways that their scopes differ substantially from one another. We have observed how some teachers become genuine lighthouses that cast the light on the way to be trodden, while others equal themselves with the students, almost adopting the position of a fellow classmate in a thematic discussion group. The actions of some teachers are error-centered, through the use of subtle and well defined techniques aiming at taking care and strengthening communications, while others display a technique we call "teacher-at-the-rescue" destined to encourage the forum and deepen the exchanges within this environment.
\end{abstract}

\section{RESUMEN}

En este trabajo se exhiben los resultados de una investigación ${ }^{1}$ realizada sobre las prácticas de enseñanza que llevaron a cabo diferentes profesores en foros de discusión de cursos que se desarrollaron en modalidad a distancia, en tres instituciones educativas, dos argentinas y una uruguaya, con propuestas y formatos bien diferentes. Los foros estudiados eran cerrados, y en ellos participaron únicamente los alumnos inscriptos en los cursos.

En la investigación subyace la concepción de que el foro es una de las herramientas centrales en una propuesta de educación a distancia. Su potencia radica en que a través de él se puede vertebrar la socialización del grupo virtual, perfilando una comunidad de sujetos todos ellos relacionados entre sí y con el objetivo común de construir conocimiento.

Esta comunicación describe las observaciones realizadas y el análisis efectuado sobre las intervenciones de docentes en los foros estudiados en el marco de la investigación. Entre otras consideraciones, se muestra cómo el papel del docente trasvasa la propuesta institucional: con un mismo formato de curso, los docentes asumen roles bien diferentes y conducen los foros en forma tan distintas que los alcances que logran difieren sustancialmente unos de otros. Hemos observado cómo algunos docentes se transforman en verdaderos faros que iluminan el camino a seguir, en cambio otros asumen un papel de contertulio, adoptando casi la posición de un integrante 
más en una tertulia temática. Las acciones de algunos docentes están centradas en el trabajo sobre el error, utilizando técnicas sutiles y bien delineadas para cuidar y fortalecer las comunicaciones, mientras que otros despliegan una técnica que hemos denominado "docente al rescate" destinada a dinamizar el foro y a profundizar los intercambios que ocurren en él.

\section{I NTRODUCCIÓN}

El desarrollo actual de las tecnologías de la comunicación y la información posibilita la creación de nuevos escenarios educativos que permiten articular un conjunto de herramientas tecnológicas que facilitan el desarrollo de nuevas actividades educativas. Las comunicaciones se potencian por medio de interacciones electrónicas ágiles y dinámicas. Esta modalidad de enseñanza tiene características específicas en tanto crea un espacio diferente al convencional para implementar situaciones de aprendizaje. Por su particularidad, las prácticas de enseñanza son distintas a las que tienen lugar en el aula. Las relaciones interpersonales entre docentes y estudiantes también tienen rasgos singulares ya que ellas están mediadas por la tecnología.

Este trabajo de investigación aborda uno de los temas de la nueva agenda educativa: las prácticas de enseñanza en entornos virtuales. El estudio centra su atención en los procesos de enseñanza que realizan los docentes cuando moderan foros de discusión en cursos universitarios de nivel de postgrado que se desarrollan en la modalidad a distancia. Intenta identificar los aspectos que favorecen el aprendizaje y cómo se enseña cuando la comunicación está terciada por soportes telemáticos. Interesa descubrir algunos indicios que aporten a la reflexión sobre las buenas prácticas de enseñanza a distancia.

La mirada está focalizada en cómo el docente lleva adelante su tarea de enseñante en un entorno que en principio le es novedoso y que no cuenta con una didáctica específica para la transposición de conocimientos. La situación de enseñanza es esencialmente diferente debido a que las relaciones personales no son cara a cara sino que están interpuestas por la tecnología y porque la comunicación se limita a un solo canal: el textual. Además, salvo excepciones, la formación de los docentes ha sido en clases convencionales lo que implica que no tienen experiencias personales de aprendizaje en línea ni profesores memorables de cursos a distancia.

Desde nuestra perspectiva, el foro es una de las herramientas centrales en una propuesta de educación a distancia. Su potencia radica en que a través de él se puede vertebrar la socialización del grupo virtual, perfilando una comunidad de sujetos todos ellos relacionados entre sí y con el objetivo común de construir conocimiento, a decir de Wenger (2001) construyendo una "comunidad de práctica". El docente como moderador del foro de discusión adquiere un papel relevante en tanto participa del proceso de construcción de significados a través del diálogo e intercambio con los alumnos. Esto convierte a las herramientas de comunicación en la base material de los procesos formativos en los entornos virtuales. En este espacio educativo se pueden crear las condiciones para que las relaciones interpersonales se conviertan en más democráticas o dialógicas de modo que alumnos y docentes participen de intercambios comunicativos en un gradiente de complicidad creciente (Domínguez, 2004).

El estudio se enmarca en las teorías cognitivistas que describen la dinámica de los procesos de aprendizaje. Parte de las teorías clásicas de constructivismo de Piaget que destaca las fuerzas propias del sujeto, con el apoyo de la teoría histórico-cultural de Vygotsky (1979) que atiende a los aspectos socioculturales del individuo y considera que en la adquisición del conocimiento están implicados factores exógenos como las influencias interpersonales y la mediación de la cultura. Incorporamos las aportaciones de Resnick (1989) y Meyer (2000) que centran la atención en el aprendizaje activo, las que conciben al estudiante con un papel protagónico, como un alumno participante, implicado y activo constructor del conocimiento. Estos 
autores consideran que el aprendiz debe desenvolver destrezas metacognitivas para hacer conscientes sus procesos de aprendizaje. En una correspondencia lógica de estos supuestos, la propuesta de la enseñanza se centra en la actividad del aprendiz. El rol del profesor aparece como coparticipante con el alumno en un proceso de congnición compartido, esto es en la construcción conjunta de significados en una situación dada. Es así que las teorías constructivistas en entornos virtuales también pueden conjugarse con los supuestos de la teoría del aprendizaje social aplicado a las comunidades virtuales. El docente actuará para generar en estas comunidades compromiso mutuo, consciencia de empresa conjunta, repertorio compartido, construcción y negociación de significados, participación activa y no participación observante o periférica (Wenger, 2001). Los instrumentos que ofrecen en la actualidad las tecnologías de la información y la comunicación tienen por misión ayudar a los estudiantes a aprender de manera significativa. Los dispositivos cognitivos permiten ampliar, potenciar y reorganizar las capacidades de los estudiantes trascendiendo las limitaciones individuales (Jonassen, 2000). En la interacción con el otro, las capacidades individuales se expanden. Las ideas fluyen y el pensamiento crítico entra en juego. El diálogo que tiene lugar en el foro puede convertirse en un instrumento cognitivo en tanto desarrolle las habilidades del pensamiento reflexivo.

\section{PERSPECTIVAS TEÓRICAS PARA EL ANÁLISIS DE LOS I NTERCAMBIOS EN LOS FOROS}

\subsection{La educación a distancia: un nuevo escenario educativo, una nueva complejidad}

Como un pesado legado, persiste hoy en algunos ámbitos la idea de que la educación a distancia se conforma con diseñar cursos de aprendizaje autónomo sobre la base de materiales autosuficientes para sustituir las clases presenciales. Nuestra concepción es bien diferente ya que consideramos que los materiales, por mejores que estén diseñados, por sí solos no completan el complejo acto de conocer. Sabemos que una clase convencional no puede asegurar los logros en el aprendizaje, por lo tanto no es posible pretender reemplazarla por materiales, por más bien que estén diseñados (Litwin, 2003). Los espacios de reflexión colectivos adquieren una importancia sustantiva en nuestra propuesta. Es allí, en donde a través del debate, docentes y estudiantes socializan el conocimiento. El aprendizaje se realiza a través del intercambio de ideas, de experiencias, de preocupaciones, en la profundidad de las discusiones. Tanto la teoría psicogenética de J. Piaget (1975), los enfoques socio-interaccionistas de L. Vygotski (1977) y J. Bruner (1988) o el cognoscitivista de D. Ausubel (1987), coinciden al menos en un aspecto: el aprendizaje es un proceso activo de construcción social de conocimientos mediado por el lenguaje y la cultura. Esto contradice la teoría subyacente de los modelos exógenos, que suponen procesos pasivos e individuales de asimilación y prescindentes del entorno cultural.

En los foros de discusión de los cursos a distancia, los docentes pueden crear estrategias pedagógicas que logren desarrollar procesos de enseñanza similares a los que tienen lugar en las clases convencionales. El desarrollo actual de la tecnología favorece la creación y el enriquecimiento de propuestas para la construcción del conocimiento y nuevas formas de encuentro entre docentes y estudiantes y entre alumnos entre sí (Litwin, 2003). Las estrategias de enseñanza están vinculadas con el qué enseñar y con el cómo enseñar. Este vínculo se basa en una concepción del aprendizaje, en nuestro caso, la teoría cognitivista.

Como cualquier otra, la propuesta didáctica en los cursos a distancia está enmarcada por el tiempo y el espacio, los recursos y los materiales, y por las características de los estudiantes. En los foros de discusión creamos un entorno que favorece el intercambio, fomentando la socialización para lograr el aprendizaje crítico, comenzando con los estudiantes en lugar de atender la disciplina o los materiales. Se busca conseguir atención y no perderla para que los alumnos se comprometan con el proceso de aprendizaje. Mediante actividades variadas, el docente 
puede ayudar a los estudiantes a aprender, fomentando el razonamiento disciplinar. Puede desarrollar tareas orientadas a recuperar la información, orientar y reorientar los procesos de comprensión y de transferencia, revisar los materiales, revisitar los mensajes publicados por los participantes en el foro, negociar con el grupo virtual, juzgar y elaborar criterios. El soporte tecnológico favorece la interactividad pero lo que verdaderamente determina una buena propuesta de educación a distancia son los contenidos y las actividades que se desarrollan en tanto éstos generen buenos aprendizajes, es decir, la concepción didáctica que la sustenta.

Como toda nueva modalidad comunicativa, la interactividad presenta una serie de problemas nuevos y pone de manifiesto problemas viejos de una manera actualizada (Burbules y Callister, 2001). Entre otros, mencionamos el problema de la interpretación de los mensajes; el de la libre interacción ya que el ámbito del sistema afecta las reacciones y actitudes de los interlocutores; la posibilidad de fracaso debido a la falta de competencias en el uso del medio; un soporte inadecuado, lento e insuficiente, para llevar a cabo la interacción; la frustración operada por el interlocutor por el efecto del retorno, que se pone de manifiesto cuando el tiempo de la respuesta no satisface su concepto de velocidad.

La interactividad que tiene lugar en el foro de discusión constituye en sí misma un espacio que es percibido como lugar de la comunicación y el intercambio, un entorno tecnológico de naturaleza envolvente y penetrante (Colombo, 1995). Este espacio adquiere la dimensión de un ámbito social y en él la identidad social constituye parte del fenómeno de la comunicación. Los nuevos medios permiten crear un entorno cultural dentro del cual existe una circulación continua de mensajes con una profunda interacción humana.

Una cuestión relevante en la comunicación que tiene lugar en el foro es que se produce a través de un único canal: el texto. La semiótica contemporánea considera que el texto puede ser objeto de múltiples lecturas y no una estructura secuencial en el interior de la cual es posible un único recorrido imaginado por el autor (Aroldi et al, 1995). El texto transmite contenido, significado y socialización. La gran riqueza de la comunicación escrita se evidencia en cuanto a que el lector al entrar en contacto con el texto lo resignifica, lo interpreta con gran libertad, construye nuevos significados que a su vez forman parte de los códigos intercambiados en la comunidad virtual (Nunberg, 1998).

A partir de estas cuestiones analizadas, consideramos que un buen programa de estudio para la educación a distancia da cuenta de un cuerpo docente preocupado por la comprensión de los estudiantes y atento a la complejidad que supone la comunicación mediada por la tecnología. Una propuesta educativa adecuada a esta modalidad supone flexibilidad de su implementación, no respondiendo a un modelo rígido sino a una organización que permita ajustar en forma permanente las estrategias aplicadas (Litwin, 2003).

\subsection{Los foros de discusión}

Desde la perspectiva tecnológica, los foros de discusión² son una aplicación en el formato web, un sistema informático que los usuarios utilizan accediendo a un servidor a través de Internet o de una intranet. Por lo general, los foros en Internet existen como una herramienta de comunicación en donde se invita a los participantes a discutir y a compartir información relevante en torno a un tema de interés común, en un debate libre, y con lo cual, mediante un uso pedagógico, se puede producir un gran entramado social de modo de fortalecer las interacciones interpersonales con el objetivo de formar una comunidad de aprendizaje. Este soporte telemático permite establecer "una conversación electrónica" sin necesidad de estar presentes físicamente en un mismo lugar ni coincidir en el mismo tiempo. Dentro del mismo se intercambian mensajes, los que son publicados en una sección o página web, respetando el orden de las intervenciones, las que se 
enlazan conforme fueron generadas, desplegándose en pantalla la relación completa de intervenciones con su estructura dinámica, es decir, pudiéndose observar lo que opinó cada uno y la secuencia de intervenciones que produjo en los demás. Los foros constituyen una de las estrategias interactivas que buscan propiciar estos intercambios virtuales interpersonales, generando un espacio de colaboración y discusión, por ello que también se les denomina, muy apropiadamente, foros de discusión en Internet, grupos de diálogo o conferencias electrónicas (Icaza, 1999).

La acción del docente es clave para dinamizar los foros y provocar intercambios significativos. En una primera fase, en los foros de discusión la cohesión social es débil. Es el docente que, con estrategias comunicativas adecuadas, procura su fortalecimiento y la construcción de un entramado social que alcance a constituir una verdadera comunidad de aprendizaje. Conduce la conversación de tal forma de convertirla en un diálogo educativo. La comunicación que tiene lugar en una primera instancia corre el riesgo de ser vaciada de contenido, ser superficial y poco significativa. Tiende a ser manipulada, en la mayoría de las veces en forma inconsciente, por los sesgos personales y por la banalización y la trivialidad, aspectos que predominan en las comunicaciones cotidianas en nuestra era posmoderna. Es más fácil situarse en el plano de la información que producir intercambios que conciernen pensamientos profundos que puedan en última instancia provocar rupturas y transformaciones personales (Wolton, 2006). La tendencia inicial es de poco compromiso personal en la construcción del conocimiento; es más fácil ubicarse en el plano de la información. Ella fluye y nos mantiene al resguardo del riesgo del cambio. No es suficiente que los mensajes y las informaciones circulen con rapidez, su función primordial es el enriquecimiento de la vida personal y democrática en el seno de la comunidad.

En los foros, el orden y la fluencia del intercambio comunicativo adquieren un ritmo propio. Un fuerte intercambio de mensajes y una interacción fluida no es sinónimo de comunicación. Para que tenga lugar la comunicación es necesario asumir que el receptor tiene su propio estatus. Y aquí se plantea uno de los principales problemas de la comunicación cuando el emisor entiende que tiene algo importante y legítimo para transmitir, dando por sentado que los receptores no podrán sino que asentir. En la verdadera comunicación esto no es cierto: el otro tiene su propia individualidad y perspectiva del asunto, no sólo podrá disentir, sino que además pondrá en riesgo la legitimidad e importancia de la cuestión (Wolton, 2006). Una comunicación auténtica con el otro es entrar en su problemática, es comprometerse con el otro asumiendo los riesgos que ello implica. Dado este panorama, no sorprende que en una primera instancia el entramado social del foro sea débil. Hay que tejerlo mediante el diálogo pedagógico y una comunicación auténtica.

Pero no toda interacción conversacional con el otro supone un diálogo. Según Burbules (1993), el diálogo implica un compromiso con el proceso mismo de intercambio comunicativo, una disposición para alcanzar acuerdos significativos entre los participantes con el propósito de arribar a un nuevo descubrimiento, una nueva comprensión, que mejora el conocimiento, la inteligencia o la sensibilidad de los que toman parte en él. La comunicación no se reduce a intercambiar información entre personas que no comparten necesariamente los mismos valores e intereses, sino que, sobre todo, implica la aceptación del otro, estableciendo relaciones sociales que contribuyen al mejor desarrollo de la vida de los seres humanos (Wolton, 2006).

La comunicación en el foro no se reduce al desarrollo de las habilidades técnicas para manejar la herramienta. No es suficiente que los mensajes y las informaciones circulen con rapidez: su función primordial es el enriquecimiento de cada uno compartiendo las visiones de los otros, con una actitud auténticamente democrática. Aceptar al otro y defender la propia identidad. 
A menudo se entiende algo distinto de lo que el emisor dice o desearía que se comprendiera. El receptor en línea recibe el mensaje y su libertad consiste en, precisamente, aceptar, repensar, negociar ese mensaje. Esto es parte de la compleja realidad de la comunicación y la razón de sus desfases incesantes (Wolton, 2006). El receptor nunca es pasivo, interpreta desde su individualidad los mensajes que recibe, por lo tanto actúa. A menudo ocurre que no se expresa directamente. Esto no debería hacer suponer al emisor que la conversación está finalizada. Tendrá que volver a interactuar con él para darle realmente contenido a esta comunicación.

Al foro hay que concebirlo como un lugar de encuentro pedagógico y de acción pedagógica en términos de socialización en valores democráticos, a decir de Bridges (1988), para desarrollar una cultura moral en la discusión grupal. Esto implica promover un "clima áulico" que aliente y apoye la racionabilidad, la solidaridad, el sosiego, la veracidad, la libertad de participar, la igualdad y el respeto mutuo. Cuando se participa en el foro hay que desplegar lo que Burbules (1993) denomina las virtudes comunicativas, o sea las disposiciones y prácticas que contribuyen a mantener buenas relaciones comunicativas, como ser la tolerancia, la paciencia, la disposición a recibir críticas, la apertura para reconocer el propio error, la capacidad para entender al otro con cuidado y atención. El diálogo se empobrece si no surgen visiones encontradas, cuestionamientos o desacuerdos. Pero cuestionamientos o desacuerdos sin compromiso personal con el otro harán que el proceso comunicativo se interrumpa (Burbules, 1993).

\section{ANALISIS DE LAS I NTERACCIONES EN LOS FOROS ESTUDI ADOS}

La investigación se realizó en nueve foros de discusión de cinco cursos diferentes, involucrando a siete docentes pertenecientes a tres instituciones distintas dedicadas a la formación docente a nivel de postgrado, dos ubicadas en la República Argentina y la otra en la República Oriental del Uruguay. Se optó por seleccionar a estas tres unidades académicas en virtud de que en ellas se vienen desarrollando desde hace varios años actividades de formación en modalidad a distancia, con tres propuestas de cursos bien diferentes. Los docentes que participaron en el estudio tienen una vasta experiencia en prácticas de enseñanza en esta modalidad. Los foros estudiados corresponden a cursos con matrícula (cursos reglados) por lo tanto en ellos participaron únicamente los alumnos inscriptos. Las propuestas curriculares de las tres instituciones que participan en este estudio promueven la participación de los estudiantes en los foros, pero no existe una obligación impuesta para que publiquen mensajes.

Previo al análisis de los mensajes publicados en los foros por docentes y estudiantes, se establecieron cuáles eran las dimensiones comunicacionales relevantes a utilizar en el estudio y que fueran coherentes con el marco teórico presentado en el capítulo anterior.

\subsection{Las dimensiones comunicacionales en los mensajes de los docentes}

A continuación presentamos las dimensiones comunicacionales que pautaron el análisis de los mensajes publicados por los docentes.

a) Reparadores. Refieren a los mensajes en donde el docente trabaja el error desde una concepción piagetiana del aprendizaje, en el supuesto de que contribuye a desarrollar el conocimiento en la medida que el estudiante tenga conciencia de sus errores en el proceso interpretativo.

b) Conceptuales. Mensajes en los cuales el docente incorpora a la discusión elementos del plano conceptual. Inscribe cuestiones teóricas, refiere e introduce elementos de la bibliografía recomendada.

c) Reflexivos. Aluden a mensajes que contienen una reflexión interesante o profunda pero en la cual no se incorporan elementos del marco teórico. 
d) De andamiaje. Refieren a los mensajes en donde el docente cuestiona o interpela, busca andamiar la construcción de conocimientos en una visión vygostkiana para construir y profundizar los conceptos teóricos.

e) Socioemocionales. Mensajes que tienen la finalidad de contener emocionalmente al alumno, lo alientan, lo animan, lo motivan, le da acogida para que se sienta acompañado en el proceso de aprendizaje. Con un lenguaje cálido, generan empatía y colaboran con la formación de un buen clima en el espacio virtual de socialización.

f) Orientadores. Mensajes que publica el docente con la intencionalidad de orientar y encauzar la discusión.

g) Sociocognitivos. Intervención del docente destinado a animar la participación. Promueve la presencia activa de los estudiantes, los integra al grupo y fomenta la incorporación de elementos teóricos en las reflexiones.

h) Laterales. Mensajes que contienen cuestiones o comentarios laterales, que no tienen que ver con el desarrollo del tema o con la resolución de la actividad planteada. Aparecen saludos, agradecimientos o comentarios sobre asuntos operativos $u$ organizativos del curso o del uso de las herramientas tecnológicas.

\subsection{Las dimensiones comunicacionales en los mensajes de los estudiantes}

Los mensajes de los alumnos que participaron en los foros se analizaron en base a las siguientes dimensiones comunicacionales.

a) Autoexperienciales. Refieren a mensajes que contienen relatos de experiencias personales o refieren a situaciones vivenciales. No incorporan reflexiones enriquecidas con la teoría sino que se ubican solamente en el plano de la experiencia personal.

b) Experienciales. Mensajes que relacionan con las experiencias de otros, tampoco incorporan reflexiones enriquecidas.

c) Reflexivos. Aluden a mensajes que contienen reflexiones interesantes o profundas pero en los cuales no se incorporan elementos del marco teórico.

d) Interrogativos. Denotan una reflexión que lleva al estudiante a interrogarse, a plantear dudas sobre aspectos de la temática del curso.

e) Significativos. Construyen conceptos, crean, innovan, incorporan teoría a sus reflexiones. Incorporan reflexiones profundas con elaboraciones teóricas enriquecidas.

f) Laterales. Mensajes que contienen cuestiones o comentarios laterales, que no tienen que ver con el desarrollo del tema o con la resolución de la actividad planteada. Aparecen saludos, agradecimientos, consultas sobre asuntos operativos u organizativos del curso o sobre aspectos tecnológicos.

\section{DESCUBRI MI ENTOS Y HALLAZGOS}

Esta investigación realiza una mirada sobre los foros de discusión desde la perspectiva de las buenas prácticas de enseñanza en entornos no presenciales. La tarea de indagación está centrada en obtener algunos hallazgos o descubrimientos y en la construcción de categorías teóricas, las cuales responden a nuestro enfoque como investigador, con vigilancia epistemológica y bagaje de conocimiento teórico, pero con un sentido interpretativo propio, como afirma Sautu (2003), miramos lo que somos capaces de ver, construimos evidencia empírica a partir del marco teórico que nos impregna, ideas y conceptos que subyacen en nuestra mente. 


\section{a) EI foro en relación con la institución}

\section{Los foros transparentan al docente. La propuesta institucional no limita sus prácticas de enseñanza}

Cuando se analizan las propuestas de enseñanza de los docentes, existe a priori la idea que ellas responden a se ven fuertemente enmarcadas por el proyecto institucional. Los foros estudiados en esta investigación pertenecen a tres instituciones con diferentes propuestas de trabajo ¿hay por lo tanto tres estilos distintos de proyectos de enseñanza?, ¿los docentes de un mismo centro se ubican en una misma categoría o son capaces de trasvasar el proyecto institucional? Las observaciones del trabajo de campo indican que esta idea previa no se confirma. Por el contrario, encontramos que los docentes asumen roles bien diferentes a pesar de estar bajo un mismo marco de referencia. Mientras unos ocupan la posición de contertulios con intervenciones que hacen desde el lugar de un participante más en una tertulia temática, sin una actitud decidida para imprimirle rumbo al debate, sin incorporar teoría a las reflexiones y sin provocar en los demás participantes reflexiones enriquecidas incluyendo contribuciones referidas a la bibliografía recomendada, otros, trabajando en un curso igualmente estructurado en la misma Institución, asumen un papel protagónico, con una forma de conducción y comunicación estratégicamente elaborada, la que hemos denominado "docentes al rescate" ya que a partir de los mensajes publicados por los alumnos, rescatan y recuperan algún elemento novedoso para usarlo como trampolín, mediante una pregunta sagaz, para que los materiales de estudio sean revisitados con el fin de desentrañar las respuestas y clarificar los conceptos. Orientan, animan, provocan la participación de los estudiantes, proponen líneas de debate, desarrollan teoría y explicitan posiciones teóricas personales, todo lo que incita a una discusión fermental y profunda. La misma institución, el mismo formato de curso, propuestas de enseñanza bien diferentes. Objetivos y formas de trabajar diferentes provocan distintas respuestas de los estudiantes.

Algunos docentes tienen una participación muy activa, son locuaces e histriónicos. Provocan, a partir de las vivencias personales, la lectura de la bibliografía que consideran básica para adentrarse al conocimiento de la materia. Otros en cambio, denotan como preocupación central mantener la dirección de las discusiones con el fin de construir conocimiento a partir de la contención emocional. Imprimen al diálogo mucha calidez, generando en los alumnos beatitud en el espacio virtual, facilitando la socialización de las vivencias personales, para que a partir de ellas reflexionen e incorporen teoría.

En las mismas Instituciones, bajo una misma propuesta, se observan estilos de conducción de los foros bien diferentes. Las prácticas de enseñanza trascienden lo institucional para adquirir la impronta que cada docente le da de acuerdo a sus características personales y a su historia de formación profesional.

\section{b) El foro con un sentido pedagógico}

\section{Los foros como herramientas para la construcción de conocimiento}

Los objetivos de los foros pueden ser muy diversos. Encontramos los foros de intercambio social, comúnmente denominados cafés, en los cuales se consolidan las relaciones interpersonales, clave para generar un buen ambiente de trabajo colaborativo. Existen también los foros de novedades en donde se intercambian noticias e informaciones respecto a los cursos. Identificamos los foros centrados en la contención emocional del alumno, en donde básicamente se intercambian experiencias y vivencias personales, procurando mantener motivado al alumno evitando su aislamiento y el sentimiento de soledad, factores que frecuentemente terminan provocando abandono de los cursos. Pero también existen los foros focalizados en la construcción de conocimiento es el caso del primero de los foros estudiados. En él se observa que prácticamente 
la mitad de los mensajes enviados por los alumnos incorporan teoría a sus reflexiones. Este foro está dirigido por un docente que, a partir de las actividades propuestas, promueve la lectura de la bibliografía recomendada para el curso, generando un intenso intercambio de mensajes con contenidos profundos y reflexiones teóricas. El diálogo generado en el foro, a partir de una propuesta didáctica apropiada, contribuye con la construcción del conocimiento. Una situación similar se observa en los foros dirigidos por los dos últimos docentes estudiados. Éstos utilizan una estrategia de intervención con clara intencionalidad de provocar un intercambio relevante. La mayoría de las intervenciones contienen reflexiones enriquecidas. Los alumnos innovan, investigan, incorporan teoría.

El análisis de los datos recabados en la investigación permite afirmar que los participantes tienden a elaborar conceptos cuando el docente imprime una acción decidida en este sentido. El papel del docente es clave: una conducción que enfatiza la construcción del conocimiento estimula intercambios significativos. Una buena propuesta de enseñanza puede provocar, a través de los intercambios que se producen en el foro, reflexiones enriquecidas y construcción de conocimiento.

\section{c) Contener}

\section{El primer paso para provocar participación}

El primer paso es la contención. Esto es lo que hacen los profesores que logran mayor interactividad y más profundidad en las discusiones que tienen lugar en sus foros. Responden a los mensajes de los alumnos en forma rápida, a manera de devolución y para sostenerlos emocionalmente. Procuran crear un ambiente cálido y propicio para el intercambio y el aprendizaje. Se presentan en el foro como conductores del proceso de enseñanza, no como expertos en contenidos con los cuales sólo se puede interactuar si se posee mucha información o conocimiento del tema en cuestión. En general estos docentes proponen una actividad que moviliza el campo emocional de los estudiantes, partiendo de la narración o evocación de experiencias biográficas con el fin de que sean socializadas en el grupo. Se ofrece a los estudiantes un diseño cercano, propio, abordable, no de una altura intelectual para la cual, en una primera etapa, aún no están preparados. Este es el modo de interactuar de cuatro de los siete docentes estudiados cuyos foros fueron los más ricos en cuanto a participación y niveles de discusión.

\section{d) Docentes al rescate}

\section{Una estrategia para la construcción del conocimiento}

Hemos denominado "docente al rescate" al modelo de intervención que fue implementado por dos de los docentes estudiados. A modo de contención, el docente interviene en el foro ante cada mensaje publicado por los alumnos. Los mensajes de los docentes son iniciados con unas primeras líneas orientadas a crear un clima cálido de comunicación que favorece el intercambio y la construcción de conocimiento, incluso desde el error. En la segunda parte de estos mensajes se observa que con clara intencionalidad de generar intercambios teóricos profundos, recuperan o "rescatan" conceptos vertidos por los alumnos. A partir de ellos, animan a continuar participando en el foro o desarrollan teoría para finalizar con el planteo de interrogantes para que los alumnos vuelvan a reflexionar sobre ellos, los profundicen y de este modo construyan conocimiento.

Como una estrategia cuidadosamente elaborada, "docente al rescate" se convierte en una propuesta de intervención en donde el docente resguarda al alumno, elogiándolo, subrayando el valor de su participación, constituyendo de este modo una fuerte tarea de contención. Luego recupera de los mensajes publicados algún elemento interesante, novedoso, que permita abrir 
una línea de análisis donde se lo enmarca en el campo teórico para finalizar con una pregunta o una serie de interrogantes que obligan a los alumnos a acudir a las lecturas recomendadas para construir los conceptos.

\section{Modelo de estrategia de intervención del "docente al rescate”}

El docente responde cada mensaje de los alumnos como forma de devolución (modelo 1 a 1)

Crea un clima de comunicación que favorece el intercambio y la construcción de conocimiento, incluso desde el error.

Crea un espacio que favorece el intercambio enriquecido.
Rescata o recupera un aporte del estudiante.

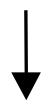

Alaba su aporte generando un buen clima, lo apaña emocionalmente.

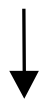

Anima a participar.
Construye teoría

CONTIENE

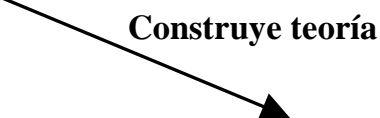

Rescata o recupera un concepto vertido por el alumno en su intervención.

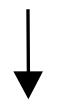

Desarrolla teoría en torno a este concepto.

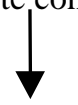

Plantea una serie de interrogantes respecto a este concepto para que el alumno vuelva a él, lo profundice y construya conocimiento. 


\section{e) El modelo “1 a 1".}

\section{Provocando participación en el foro}

No todos los docentes lo emplean, pero quienes lo hacen provocan una gran participación de los alumnos en el foro. El modelo " 1 a 1" refiere a que el docente publica un mensaje a modo de devolución, ante cada una de las intervenciones de los alumnos. Una intervención de un alumno implica una intervención del docente. Los alumnos se sienten contenidos emocionalmente, sienten que el docente está atento a sus intervenciones, interesado en ellos y en el curso. Esto disminuye el sentimiento de aislamiento que muchos alumnos experimentan al participar en cursos no presenciales. Esta estrategia de intervención exige al docente una activa participación, una dedicación extrema durante el tiempo que está abierto el foro. Los datos que surgen en nuestra investigación muestran que los foros con más participación son aquellos en los que el docente interviene en un modelo " 1 a 1". Las observaciones de nuestro trabajo son similares a las que aportan otras investigaciones (Garrison y Anderson, 2003; Barberà, 2004; Ehuletche, 2007); la frecuencia de las interacciones de los docentes constituye uno de los componentes de mayor significatividad en la dinámica interactiva de un grupo virtual. Las intervenciones de los alumnos aumentan conforme la presencia del docente es más intensa. Una intervención intensa del docente provoca que los alumnos se involucren y se comprometan más con los cursos.

\section{f) Los distractores que disgregan}

\section{Recursos que provocan efectos distintos en espacios diferentes}

El uso de los distractores es una práctica habitual que los docentes utilizan en forma casi natural en sus clases presenciales. Se emplea para reducir las tensiones cuando el desarrollo teórico ha alcanzado niveles de saturación o cuando las relaciones interpersonales llegan a umbrales de conflicto. El docente, mediante una ocurrencia, un chiste o un comentario lateral, distrae a sus interlocutores, bajando tensiones, para luego, con otra intervención oportuna, pasado un tiempo prudencial y en el momento adecuado, recuperar la atención, retornando a las actividades de clase. Cuando este recurso se aplica en un diálogo con formato no presencial, no siempre provoca el efecto esperado. Al colocar un distractor en el foro, la conversación se puede disgregar de tal forma que sea muy difícil volver a retomar la discusión en el nivel de profundidad anterior. El hecho de que la comunicación sea asincrónica, impide que el docente pueda controlar el factor tiempo, ya que el tiempo de cada participante en el foro es diferente. Esto constituye un obstáculo real para que el docente recupere fácilmente el control del debate y pueda reanudar la actividad de enseñanza. Esto se observó claramente en el primero de los foros estudiados.

TEMÁTICA PERIFÉRICA

Reflexiones que se construyen a partir de experiencias personales

TEMÁTICA CENTRAL DEL FORO

Reflexiones que incorporan teoria

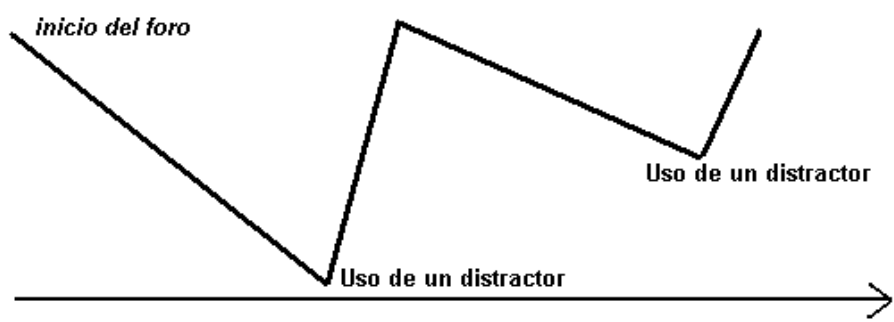

tiempo 
El gráfico muestra cómo la discusión del primer foro estudiado pasa lentamente del plano de las experiencias personales a reflexiones que incorporan teoría. Este estadio parece ser muy inestable ya que basta una pequeña disgresión para que rápidamente se vuelva al estado inicial. Con gran esfuerzo el docente logra que la discusión retorne al plano teórico pero no se alcanza la profundidad anterior. Finalmente y en forma precipitada, a partir del uso de un segundo distractor, se vuelve al plano de las reflexiones personales y superficiales sin el correlato teórico.

\section{g) El abordaje del núcleo temático del curso}

\section{Un modelo sobre la profundidad de las participaciones}

Los alumnos alcanzan niveles muy diferentes en relación a la profundidad de sus reflexiones y a la proximidad del núcleo temático del curso. Conforme se desarrolla el foro, con intervenciones oportunas del docente algunos alumnos van adentrándose en una trama conceptual, logrando superar las primeras etapas de intervenciones anecdóticas o emotivas, hasta alcanzar otras de contenidos más profundos.

La siguiente figura ilustra el modelo sobre la profundidad de las reflexiones en las intervenciones de los alumnos en el primer foro estudiado.

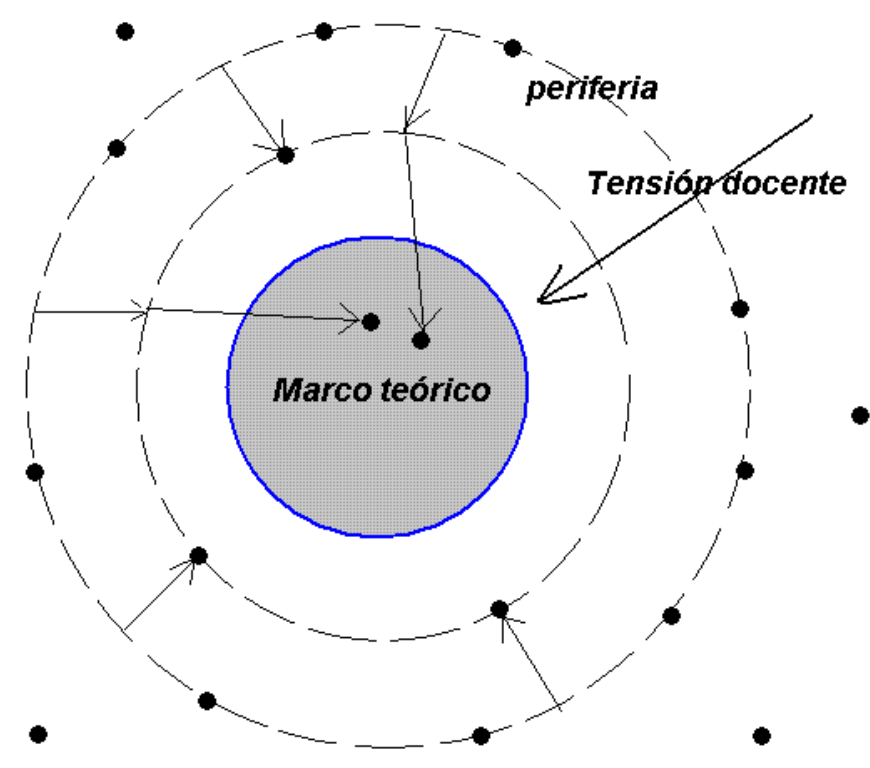


Las líneas alternadas representan estadios de profundidad que van de los más periféricos a los más nucleares. En el centro se encuentra el tema del curso en su dimensión conceptual con su marco teórico correspondiente. Los puntos indican dónde se encuentran las intervenciones de los alumnos respecto al núcleo teórico del curso. El modelo muestra que varios alumnos permanecen estáticos en niveles de discusión periféricos. Unos más cercanos, otros más distantes del núcleo temático, pero todos ellos sin ingresar a él. Otro conjunto de alumnos en cambio logra un acercamiento relativo a las cuestiones teóricas debido a la tensión con el aprendizaje provocado por el empuje del docente. Son unos pocos los alumnos que ingresan realmente al corazón de la temática del curso. Los puntos aislados fuera del núcleo y de la periferia corresponden a alumnos cuyas participaciones son comentarios laterales y sin contenido o a quienes se mantiene fuera del debate con una participación observante.

\section{CONSTRUCCIÓN DE CATEGORÍ AS TEÓRICAS}

\subsection{Las categorías de los foros}

En primer lugar presentamos la categorización que realizamos sobre los foros según el propósito que los docentes persiguen con ellos. Según esta dimensión de análisis, reconocemos tres categorías de foros, a saber:

\section{a) Foros de contención}

Varios son los formatos que tienen los foros de contención. Son muy habituales los foros de intercambio socializador, denominados "foros café" o "cafetería" en donde tienen lugar charlas de temas generales sin abordar aspectos curriculares. Tienen como objetivo aportar a la construcción social del grupo virtual. Por otro lado están los foros "novedades" en donde se intercambian informaciones y noticias sobre los cursos, una forma de acercar la institución al estudiante a modo de ofrecer un espacio para intercambiar y consultar cuestiones de orden administrativo u organizativo. Estos foros no son parte del desarrollo curricular. Existen otros foros que sí forman parte del curso y que están destinados a la contención. En estos foros se busca principalmente alentar la participación de los alumnos concomitantemente con el desarrollo temático, generando un ámbito de intercambio llano y honesto. Se trabaja en la contención de los alumnos, desde lo emocional a partir de actividades propuestas que evocan experiencias personales, convirtiéndose el foro en un espacio virtual de socialización.

El propósito del docente al animar un foro con estas características es el de dar acogida al estudiante para que se sienta acompañado en el proceso de aprendizaje en la modalidad a distancia, un formato que al estudiante, por lo menos en un principio, puede resultarle ajeno y provocarle un sentimiento de estar distante y aislado de sus profesores y compañeros. Aquí el docente está más preocupado porque los alumnos tengan presencia, manifiesten adhesión al curso y logren involucrarse con el mismo que por el desarrollo del conocimiento. En estos foros el docente trabaja desde el campo emocional, partiendo de las experiencias personales, reflexionando sobre ellas y analizando sus impactos a nivel personal.

\section{b) Foros de andamiaje}

En estos foros el docente busca andamiar la construcción de conocimientos en una visión vigotskiana para construir y profundizar los conceptos teóricos. Procura que los alumnos entren en contacto con las fuentes bibliográficas e intercambien conceptos abordados en ellas. El accionar docente está sostenido por el modelo socioconstructivista del aprendizaje: la interacción enriquecida en estos contextos virtuales permite la construcción de significados compartidos, explícitos, estructurados y complejos. Mediante el diálogo educativo, se emprende el trabajo sobre los conocimientos previos o concepciones alternativas, buscando sortear las tensiones 
dadas por los conflictos sociocognitivos para que los estudiantes aprendan en una comunidad virtual. Se pretende que sean capaces de atribuir significados a los conceptos y de construir en colectivo las representaciones mentales. En este marco, la construcción del conocimiento supone un proceso de elaboración de sentidos, estableciendo relaciones entre los mismos a modo de un mapa conceptual.

Desde esta perspectiva, el aprendizaje se construye al relacionar los conceptos nuevos con los conceptos que ya poseen y al relacionar los conceptos nuevos con la experiencia propia o las experiencias de los otros. Desde esta mirada sociocultural, la educación es un proceso de andamiaje en la construcción del conocimiento, siendo el lenguaje la principal herramienta en dicho proceso. La metáfora del andamiaje describe el papel que juega el docente en el proceso de enseñanza. Así como los andamios en una construcción constituyen el soporte que marca la dirección y la forma que adoptará el futuro edificio, así también los docentes elaboran estrategias como soportes que configuran el desarrollo cognitivo. Los andamios son necesarios y transitorios, como la ayuda que presta el docente, y se van retirando progresivamente a medida que la estructura del edificio se va construyendo y a medida que los estudiantes van adquiriendo una pericia y una autonomía mayores en la realización de una actividad (Coll y Solé, 2001). Esta propuesta se enmarca en la noción de "zona de desarrollo próximo" introducido por Vygotsky (1979) puesto que con los "andamios cognitivos" se pretende que los alumnos desarrollen las funciones superiores de la cognición.

\section{c) Foros para la resolución de actividades}

Es frecuente centrar la actividad del foro en la resolución de una tarea, ya sean reflexiones acerca de una lectura sugerida, la elaboración de un pequeño ensayo sobre el tema en cuestión, o la resolución de un problema o de un caso hipotético. Mediante estas tareas abiertas y relevantes, se pretende activar en los estudiantes tanto sus conocimientos previos y sus procesos cognitivos como la organización y elaboración de las estructuras conceptuales. El alumno desempeña un papel activo en el proceso de aprendizaje, al cual se lo concibe como un proceso de reconstrucción en el que el sujeto organiza la trama conceptual. Se suscita en el foro un diálogo en torno a los hallazgos o a las dificultades que expresan los estudiantes. El docente trabaja el error en una concepción piagetiana del aprendizaje.

Esta propuesta pedagógica parte de la concepción de que el conocimiento es una construcción que realiza el individuo a través de una actividad que pone en movimiento los instrumentos intelectuales que posee, es decir, las estructuras operatorias de su pensamiento. En este proceso de construcción del conocimiento, la teoría piagetiana asigna un papel significativo al error que el estudiante comete en su interpretación de la realidad. No son considerados como fallas, sino pasos necesarios del proceso constructivo. Se contribuirá a desarrollar el conocimiento en la medida en que el estudiante tenga conciencia de los errores en el proceso interpretativo.

\subsection{Las categorías de los docentes en los foros}

Se ha observado que los docentes asumen distintos roles cuando moderan los foros de debate. Aquí presentamos una segunda categorización en la cual la dimensión de análisis es el rol que asumen los docentes en los foros. A partir del análisis de las conductas y los comportamientos que los docentes ponen en juego en la conducción y en la presencia en los foros, construimos cuatro categorías, a saber: 


\section{a) El docente contenedor}

Es un docente que participa en el foro con el objetivo central de contener emocionalmente al alumno en un modelo de intervención que hemos denominado " 1 a 1". El docente responde a cada uno de los mensajes publicados por los alumnos. Esto anima a los estudiantes porque se sienten escuchados (leídos), acompañados, provocando mayor adherencia y participación en el foro. Plantea actividades que procuran, más que desarrollar teoría, narrar, describir o evocar experiencias personales relativas a situaciones de aprendizajes o de enseñanzas. Convierten al foro en un espacio virtual de socialización donde se ponen en juego los factores emocionales y afectivos. Con este papel, el "docente contenedor" logra desarrollar adecuadamente las etapas iniciales del proceso centradas en la opinión y la descripción de experiencias personales, pero sin duda, a medida que avanza el desarrollo del curso, es conveniente adoptar otros roles para favorecer estadios de discusión más profundos.

\section{b) El docente faro}

Otros docentes asumen un papel más protagónico en la construcción del conocimiento. Procuran incidir directamente en el rumbo que toman las discusiones del foro. Intentan provocar discusiones profundas y reflexiones enriquecidas. Hemos denominado a los docentes de esta categoría "docentes faro" puesto que iluminan la dirección del camino, dan señales luminosas que muestran el rumbo para la exploración teórica. No dan un mapa del camino a recorrer ni disponen de un canal boyado con señales luminosas a ambos costados. Marcan la trayectoria del camino a recorrer en un mar libre. Mediante sus intervenciones, ponen énfasis en la construcción del conocimiento, no centran su accionar en socializar ni en contener, sino en teorizar. Dejan transcurrir la discusión para intervenir cuando pueden abrir nuevas líneas de discusión o nuevos enfoques, incorporando al debate nuevos elementos de análisis ampliando la perspectiva teórica. En varias oportunidades ponen en relieve en la conversación un tema que, si bien fue mencionado por los alumnos, no fue suficientemente profundizado, o su análisis fue limitado o empobrecido. Conducen con decisión las líneas de discusión del debate, desarrollan teoría y explicitan su posición teórica. Estamos frente a docentes activos y protagonistas que con sus rayos de luz, tal cual un faro, marcan la dirección a transitar en el debate del foro.

\section{c) El docente contertulio}

Se ha observado que otros docentes participan en los foros a nivel de comunidad, con participaciones que se pueden confundir perfectamente con las que hacen los estudiantes. Sus mensajes, como lo hacen la mayoría de los alumnos, incluyen relatos de experiencias personales o reflexiones que no incorporan teoría. Tampoco inciden para que las intervenciones contengan contribuciones referidas al marco teórico o reflexiones sobre lecturas de la bibliografía recomendada para el curso. Son docentes que carecen de una actitud decidida para imprimirle rumbo al debate del foro. Los hemos denominado "contertulios" ya que, salvo cuando agregan consignas de trabajo o animan a participar a otros estudiantes, sus intervenciones se hacen desde el lugar de un participante más en una tertulia temática. Como unos contertulios más, acompañan la discusión que tiene lugar en el foro pero no lo conducen.

\section{d) El docente tutela}

Otra de las formas de intervención de los docentes es la que hemos denominado "docente tutela". Ésta se caracteriza por tener al docente en una actitud de vigilancia epistemológica, con poca presencia activa en el foro. Estos docentes sólo intervienen con el propósito orientar la discusión y trabajar el error. Sus intervenciones en el foro son relativamente escasas y puntuales, mantienen una actitud expectante sin intervenir mientras se producen los intercambios entre los alumnos. Los pocos mensajes publicados por ellos están focalizados en la orientación de la 
discusión con la intencionalidad de provocar reflexiones profundas. Cuestionan, interpelan y reorientan a los estudiantes procurando intervenciones de mayor profundidad. No intervienen cada vez que lo hacen los estudiantes. No buscan contener a los alumnos. Focalizan su accionar en vigilancia del proceso de construcción del conocimiento y en el trabajo del error, en una concepción piagetiana del aprendizaje.

El "docente tutela" está presente, pero deja transcurrir la conversación al ritmo natural que le imprimen las características del grupo en cuestión. No influye en forma directa sobre la dinámica comunicacional. Si el grupo es naturalmente participativo se verán publicados muchos mensajes; si no lo es, el diálogo podrá resultar exiguo y poco productivo. En nuestra investigación, el tercer docente estudiado asumió en sus dos foros el rol de "tutela". En el primero de ellos, los estudiantes participaron activamente publicando un promedio de tres mensajes cada uno. A este foro lo podemos catalogar de dinámico; en cambio, en el segundo, la participación de los mismos alumnos, realizando otra actividad, decayó abruptamente a menos de la mitad. El docente no intervino en este sentido, dejó que el diálogo transcurriera a su ritmo natural.

\section{CONCLUSIONES}

Este trabajo de investigación está centrado en reconocer buenas prácticas de enseñanza mediadas por la tecnología. Describe cómo enseñan los docentes en los foros en cursos que se desarrollan en modalidad a distancia, cuáles son sus propuestas de intervención y cómo éstas inciden para que los intercambios sean favorecedores de procesos reflexivos enriquecidos. En el capítulo anterior hemos descrito los descubrimientos y hallazgos que hemos alcanzado. Nuestra reflexión final nos lleva a pensar en los límites y riesgos que conllevan estas buenas prácticas de enseñanza que por sí mismas y en un justo equilibrio son muy potentes, pero si se conducen con demasiado énfasis en uno u otro sentido, pueden derivar en situaciones de enseñanza no favorecedoras de procesos comprensivos.

Incorporamos una nueva perspectiva al análisis haciendo crecer y disminuir, llevando al límite, las variables que definen a cada una de las categorías de los docentes. Consideramos que estas categorías son importantes en sí mismas en tanto tienen un fuerte poder explicativo. Conociendo sus límites éstas se potencian.

El "docente faro", como lo hemos descrito anteriormente, se caracteriza por asumir un papel protagónico en el foro provocando discusiones profundas que contribuyen a la construcción del conocimiento. Su papel es el de iluminar la dirección del camino, dar señales luminosas que muestren el rumbo para la exploración teórica. Marca la trayectoria a recorrer en un mar libre para evitar naufragios. Pero si ese protagonismo aumenta a un extremo, deja de ser un rayo de luz que traza una dirección para convertirse en un canal boyado con luces a ambos lados, permitiendo desplazar la nave sólo por el camino señalizado. En este límite el docente asume prácticas convencionales, convirtiéndose en un profesor dirigista que no da lugar a la actividad creadora e innovadora y que no promociona el desarrollo de nuevas ideas. Si por el contrario el "docente faro" abandona su rol protagónico y se recuesta en el otro extremo, en lugar de dirigir el foro, pasa a integrarlo como un "contertulio": sus intervenciones serán desde el lugar de un participante más en una tertulia temática, como un integrante de la comunidad que acompaña la discusión pero que no la conduce.

El "docente contenedor" trabaja en la contención emocional de los alumnos, colabora en la construcción de espacio virtual de socialización dándole acogida al estudiante para que se sienta acompañado en el proceso de aprendizaje. Está más preocupado porque los alumnos tengan presencia, que manifiesten adhesión al curso y logren involucrarse, que por el desarrollo mismo del conocimiento. Pero, si sólo se trabaja en los componentes socioemocionales y se deja de 
lado completamente los aspectos conceptuales, el debate del foro se puede transformar en una buena charla de café. Si por el contrario se ignoran los aspectos de contención, si el docente se presenta en el foro como un experto de altura intelectual inalcanzable con el cual sólo se puede interactuar una vez que se posea mucha información o conocimiento del tema en cuestión, lo más probable es que se quede solo. De darse esta situación, la comunicación seguramente quedará interrumpida, y en el foro prácticamente no se producirá interacción.

La principal característica del "docente tutela" es la de adoptar una actitud vigilante, con poca presencia activa, interviniendo fundamentalmente para trabajar el error utilizando una cuidadosa elección entre el uso del foro público y el correo electrónico privado para señalar cuestiones a reconstruir. El riesgo de una actitud extrema en el tratamiento del error consiste en estructurar las construcciones teóricas cayendo en una postura prescriptiva tal cual hace un chef cuando instruye en la aplicación de una receta culinaria. Si nos trasladamos al otro extremo, estaríamos en la presencia de un docente que por no asumir el riesgo de generar un conflicto con el alumno, no trabaja el error, no colaborando con su proceso de construcción del conocimiento. En el foro se hallarían conceptos correctos junto a los incorrectos, lo bueno y lo malo juntos, como el blanco y negro que conforman el pavimento de una catedral renacentista.

Desde otro ángulo del análisis, encontramos que todos los foros estudiados responden a propuestas de educación a distancia que se inscribe en un formato lineal. Los intercambios que se producen en el foro pasan por distintas etapas conforme avanza el desarrollo de las unidades del curso. Reconocemos que se transcurre por cuatro estadios: 1) foro centrado en la opinión, 2) foro centrado en la descripción de experiencias personales, 3) foro centrado en la interpretación y 4) foro centrado en la teorización. Sucede que por la dinámica comunicacional, el primer foro del curso se inscribe con el abordaje de la primera unidad, los intercambios que tienen lugar se centran en opiniones personales ya que recién se está iniciando el proceso de socialización por lo que los aspectos conceptuales quedan en un segundo plano. A medida que avanza el curso con el tratamiento de las siguientes unidades, la profundización de los intercambios pasa desde la reflexión de las experiencias personales a la interpretación y el abordaje teórico. Recién se comienza a teorizar en las últimas unidades. Cabe preguntarse qué sucede con la profundización de los contenidos teóricos de las primeras unidades.

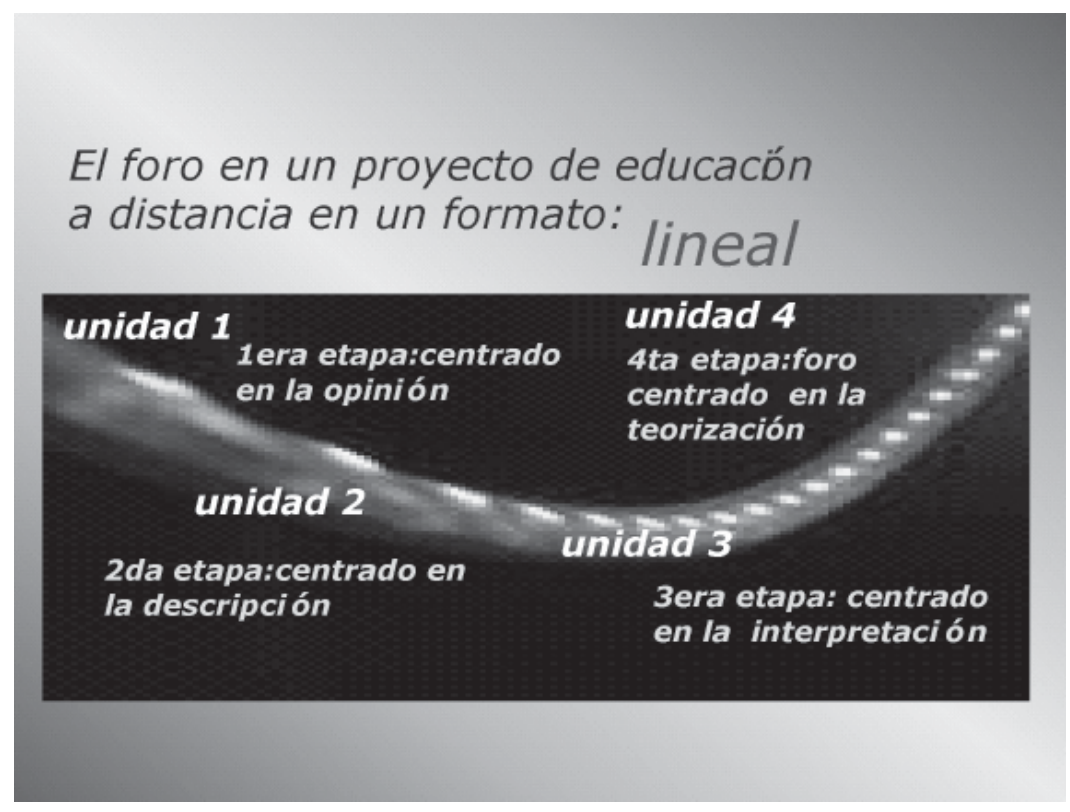


Esto conduce a pensar en la posibilidad de instrumentar otro formato para los cursos a distancia. Una configuración del tipo espiralado podría favorecer la construcción de los conocimientos en todas las unidades ya que permitiría el abordaje de cada una de ellas en estadios diferentes, conforme se desarrolla el curso. Cada unidad se revisita con un grado diferente de profundización ya que simultáneamente con el avance del curso, la construcción de red social permite desarrollar intercambios con grados mayores de teorización. A pesar de que este tipo de propuesta implica ajustar los tiempos asignados a los cursos, seguramente este formato colaborará con un mayor aprovechamiento en lo que a la construcción del conocimiento se refiere.

\section{El foro en un proyecto de educación a distancia en un formato:}

espiralado

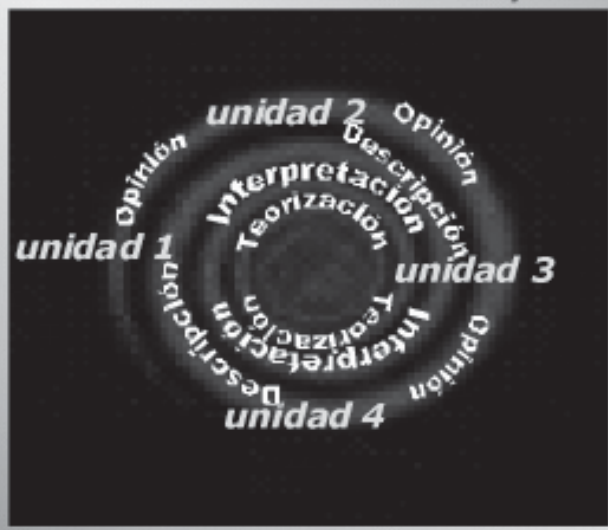

Las unidades se revisitan en los diferentes estadios del foro

En la misma línea de pensamiento de Donald L. Finkel (2008), sostenemos que la potencia de las buenas prácticas de enseñanza, ya sean presenciales o a distancia, radica en lo que se es y en lo que se hace (más allá de lo que se dice en la clase convencional o se escribe en el foro). Cuando se pretende ayudar a que un grupo de alumnos y alumnas se interesen por el conocimiento, para que lo amen y lo utilicen de manera honesta, la actitud del profesor, el trato, la preparación, la sensibilidad, la dedicación, la escucha, la observación, son formas de enseñanza no menos explícitas que la palabra (o la escritura de mensajes). "Es decir, que no sólo se da clase cuando se explica en voz alta la materia. Y sobre todo cuando se convierte la enseñanza en un proceso mediante el cual lo que está escrito en los papeles del profesor pasa a los papeles del alumno sin pasar por la cabeza de ninguno de los dos" (Santos Guerra, 2007). La dimensión moral del docente tiene que ser central en su práctica. Esto constituye una clave en la intervención docente en el foro. 


\section{BI BLI OGRAFÍ A}

AROLDI, P. et al. Conocer con los nuevos media. En: BETTETINI, G. y COLOMBO, F. 1995. Las nuevas tecnologías de la comunicación. Barcelona: Paidós. pp. 177-226.

AUSUBEL, D. et al. 1987. Psicología Educativa: Un Punto de Vista Cognitivo. México: Trillas.

BARBERÁ, E. 2004. La educación en la red. Actividades virtuales de enseñanza y aprendizaje. Barcelona: Paidós.

BETTETINI, G. y COLOMBO, F. 1995. Las nuevas tecnologías de la comunicación. Barcelona: Paidós.

BRIDGES, D. 1988. Education, democracy and discussion. Nueva York: University Press of America.

BRUNER, J. 1984. Acción, pensamiento y lenguaje. Madrid: Alianza

BRUNER, J.1988. Desarrollo cognitivo y educación. Madrid: Ediciones Morata.

BRUNER, J. 1997. La educación, puerta de la Cultura. Madrid: Visor.

BURBULES, N. 1993. El diálogo en la enseñanza. Teoría y práctica. Buenos Aires: Amorrortu.

BURBULES, N. y CALLISTER, T. 2001. Educación: riesgos y promesas de las nuevas tecnologías de la información. Barcelona: Granica.

BUCKINGHAM, D. 2008. Más allá de la tecnología. Aprendizaje infantil en la era de la cultura digital. Buenos Aires: Manantial.

CASTELLS, M. 1996. La Sociedad Red, La Era de la Información. [online] [citado 7 setiembre 2008]. Disponible en internet: http://es.wikipedia.org/wiki/Manuel_Castells

CASTELLS, M. 1998. Globalización, tecnología, trabajo, empleo y empresa. En: Revista electrónica La Factoría.(7). [online] [citado 7 setiembre 2008]. Disponible en internet: <http:// www.lafactoriaweb.com/articulos/castells7.htm>

COLL, C. y SOLÉ, I. Enseñar y aprender en el contexto del aula. En: COLL, C. et al. 2001. Desarrollo Psicológico y Educación 2. Psicología de la Educación Escolar. Madrid: Alianza Editorial. pp. 357-386.

COLOMBO, F. La comunicación sintética. En: BETTETINI, G. y COLOMBO, F. 1995. Las nuevas tecnologías de la comunicación. Barcelona: Paidós. pp. 236-257.

CROOK, Ch. 1999. Ordenadores y aprendizaje colaborativo. Madrid: Morata

CUBAN, L. 2001. Oversold and underused: Computer in the classroom. Nueva York: Teachers College Press.

DÌAZ, E. 2005. Posmodernidad. Buenos Aires: Editorial Biblos.

DOMíNGUEZ, D. et al. Metodología para el análisis didáctico de foros virtuales. Edutec '04: Educar con tecnologías, de lo excepcional a lo cotidiano. Barcelona. Noviembre de 2004. [online] [citado 10 diciembre 2007]. Disponible en internet: <http://edutec2004.Imi.ub.es/pdf/46.pdf>

EHULETCHE, A. 2007. Ajustes pedagógicos en entornos virtuales: los procesos colaborativos. [online] [citado 8 abril 2009]. Disponible en internet: <http://www.utn.edu.ar/ aprobedutec07/docs/148.doc>

EISNER, E. 2002. La escuela que necesitamos: ensayos personales. Buenos Aires: Amorrortu. 
FERNÁNDEZ, L. 1998. El análisis de lo institucional en la escuela. Buenos Aires: Paidós. FENSTERMACHER, G. y SOLTIS, J. 1999. Enfoques de la enseñanza. Buenos Aires: Amorrortu. FINKEL, D. 2008. Dar clase con la boca cerrada. Valencia: Universidad de Valencia.

FLATE, M. 1995. Moderating Educational Computer Conferences. [online] [citado 10 diciembre 2007]. Disponible en internet: <http://www.emoderators.com/moderators/morten.html>

GARRISON, R. y ANDERSON, T. 2003. Community of inquiry model. [online] [citado 8 abril 2009]. Disponible en internet: <http://edutechwiki.unige.ch/en/Community_of_inquiry_model>

GREGORI, A. Estrategias para mejorar la participación: Dinámica en foros de discusión. [online] [citado 10 diciembre 2007]. Disponible en internet:

<http://www.elearningworkshops.com/modules. php?name=News\&file=article \&sid=224>

GROS, B. 2006. El problema del análisis de las discusiones asincrónicas en el aprendizaje. [online] [citado 10 diciembre 2007]. Disponible en internet: <http://www.um.es/ead/red/16/gros.pdf>

ICAZA, J. 1999. Estrategias didácticas en grupos de diálogo electrónico. [online] [citado 10 diciembre 2007]. Disponible en internet: <http://copernico.mty.itesm.mx/ jicaza/papers/ intercambio99v2w.htm>

JACKSON, P. 1999. Enseñanzas implícitas. Buenos Aires: Amorrortu.

JACKSON, P. 2002. Prácticas de la enseñanza. Buenos Aires: Amorrortu.

JACKSON, P. 2003. La vida moral en la escuela. Buenos Aires: Amorrortu.

JONASSEN, D. El diseño de entornos constructivistas de aprendizaje. En: REIGELUTH, C. 2000. Diseño de la instrucción. Teorías y modelos. Madrid: Aula XXI Santillana. pp. 225-249.

LITWIN, E. 2001. Las nuevas tecnologías y las prácticas de la enseñanza en la universidad. [online] [citado 7 setiembre 2008]. Disponible en internet: http://www.litwin.com.ar/site/ Articulos2.asp

LITWIN, E. 2003. La educación a distancia. Buenos Aires: Amorrortu.

LITWIN, E. 2005. Tecnologías educativas en tiempos de Internet. Buenos Aires: Amorrortu. MANSUR, A. La gestión en la educación a distancia: nuevas propuestas, nuevos interrogantes. En: LITWIN. E. 2000. De las tradiciones a la virtualidad. La educación a distancia. Temas para el debate en una nueva agenda educativa. Buenos Aires: Amorrortu. pp. 53-72.

MANSUR, A. Los nuevos entornos comunicacionales y el salón de clase. En: LITWIN, E. 2005. Tecnologías educativas en tiempos de Internet. Buenos Aires: Amorrortu. pp. 129-154.

MARCELO, C. et al. Análisis del discurso y comunicación asincrónica: un sistema de análisis. Edutec '01: Congreso Internacional de Tecnologías, Educación y Desarrollo sostenible. Murcia 2001. [online] [citado 10 diciembre 2007]. Disponible en internet:

<http://www.uib.es/depart/gte/edutec/edutec01/edutec/comunic/EXP11.html>

MEYER, R. E. Diseño educativo para un aprendizaje constructivista. En: REIGELUTH, Ch. 2000. Diseño de la instrucción. Teorías y modelos. Un nuevo paradigma de la teoría de la instrucción. Madrid: Santillana. pp. 153-172.

MIRANDA, A. et al. 2007. Patrones de análisis de las interacciones en línea desde la perspectiva de la actividad. [online] [citado 22 noviembre 2007]. Disponible en internet:

<http://dialnet.unirioja.es/servlet/articulo?codigo=2284802>

NUNBERG, G. 1998. El futuro del libro. Barcelona: Paidós. 
ORELLANA, D y SÁNCHEZ, M. 2005. Técnicas de recolección de datos en entornos virtuales más usadas en la investigación cualitativa. [online] [citado 22 noviembre 2007]. Disponible en internet: <http://www.um.es/depmide/RIE/contenido/24-1_10.html>

PALINCSAR, A.S. The role of dialogue in providing scaffolding instruction. En: Education Psychologist. 1986. (21). pp. 73-98.

PIAGET, J. 1975. Problemas de Psicología Genética. Barcelona: Ariel.

RESNICK, L. y KLOPFER, L. 1989. Curriculum y cognición. Buenos Aires: Aique.

ROMAÑÁ, T. 2007. Evaluar el trabajo con foros electrónicos: propuesta de un sistema. [online] [citado 22 noviembre 2007]. Disponible en internet: <http://www.uoc.edu/rusc/4/2/dt/esp/ romana.html>

SALOMON, G. PERKINS, D. y GLOBERSON, T. Coparticipando en el conocimiento: la ampliación de la inteligencia humana con las tecnologías inteligentes. En: Comunicación, lenguaje y educación. 1992. (13). pp.6-22.

SANTOS GUERRA, M. 2007. Dar clase con la boca cerrada. [online] [citado 8 abril 2009]. Disponible en internet: <http://blog.laopiniondemalaga.es/eladarve/2007/04/12/dar-clase-con-laboca-cerrada/>

SAUTU, R. 2003. Todo es teoría. Objetivos y métodos de investigación. Buenos Aires: Lumière.

VYGOTSKY, L. 1979. Pensamiento y lenguaje. Buenos Aires: La Pléyade.

VYGOTSKY, L. 1988. El desarrollo de los procesos psicológicos superiores. Barcelona: Grijalbo.

VITTADINI, N. Comunicar con los nuevos media. En: BETTETINI, G. y COLOMBO, F. 1995. Las nuevas tecnologías de la comunicación. Barcelona: Paidós. pp. 103-171.

WENGER, E. 2001. Comunidades de práctica. Aprendizaje, significado e identidad. Barcelona: Paidós.

WOLTON, D. 2000. Internet ¿Y después?. Barcelona: Editorial Gedisa.

WOLTON, D. 2006. Salvemos la comunicación. Barcelona: Editorial Gedisa.

\footnotetext{
${ }^{1}$ Este trabajo de investigación constituyó la Tesis presentada para la obtención del Master en Educación en la Universidad ORT Uruguay. Como tutora de Tesis participó la Dra. Edith Litwin.
}

${ }^{2}$ En esta investigación los foros de discusión son cerrados, o sea pertenecientes a cursos en los que participan solamente los alumnos inscriptos en ellos, por lo que no se deben considerar foros de discusión abiertos como son las listas de distribución o grupos de discusión abiertos.

* El artículo se enmarca en la tesis de maestría del autor, dirigida por la Dra. Edith Litwin. Año 2009.

** Master en Educación abierta y a distancia, Universidad Nacional de Educación a Distancia (UNED), España. Master en Educación, Universidad ORT. Profesor de Física, Instituto de Profesores Artigas. Director, Enseñanza Secundaria, IUDEP. Coordinador de Cursos a Distancia, Instituto de Educación. 